Sādhanā Vol. 38, Part 6, December 2013, pp. 1369-1391. (C) Indian Academy of Sciences

\title{
Effect of heat input on dilution and heat affected zone in submerged arc welding process
}

\author{
HARI OM $^{1, *}$ and SUNIL PANDEY ${ }^{2}$ \\ ${ }^{1}$ Department of Mechanical Engineering, YMCA University of Science and \\ Technology, Sector 06, Faridabad 121 006, India \\ ${ }^{2}$ Department of Mechanical Engineering, Indian Institute of Technology Delhi, \\ New Delhi 110 016, India \\ e-mail: hariohm2001@gmail.com
}

MS received 26 September 2012; revised 13 March 2013; accepted 3 April 2013

\begin{abstract}
Submerged arc welding (SAW) is a fusion joining process, known for its high deposition capabilities. This process is useful in joining thick section components used in various industries. Besides joining, SAW can also be used for surfacing applications. Heat Affected Zone (HAZ) produced within the base metal as a result of tremendous heat of arc is of big concern as it affects the performance of welded/surfaced structure in service due to metallurgical changes in the affected region. This work was carried out to investigate the effect of polarity and other SAW parameters on HAZ size and dilution and to establish their correlations. Influence of heat input on dilution and heat affected zone was then carried out. Four levels of heat input were used to study their effect on \% dilution and HAZ area at both the electrode positive and electrode negative polarities. Proper management of heat input in welding is important, because power sources can be used more efficiently if one knows how the same heat input can be applied to get the better results. Empirical models have been developed using statistical technique.
\end{abstract}

Keywords. Submerged arc welding; weld dilution; electrode polarity; heat affected zone.

\section{Introduction}

Submerged Arc Welding (SAW) is primarily used in shipbuilding, pipe fabrication, pressure vessels, and structural components for bridges and buildings due to its high deposition rate (Chandel et al 1997). Other than joining, SAW is used to build up parts and overlay with stainless or wearresistant steel for example, rolls for continuous casting steel, pressure vessels, rail car wheels, and equipment for mining, mineral processing, construction, and agriculture. SAW normally

*For correspondence 
uses constant-voltage power supply and is self-regulating, so it can be used with a constantspeed wire feeder. The current is controlled by the wire diameter, the electrical stick-out, and the wire-feed speed, while the voltage is controlled by the power supply (ASM 1993). No shielding gas is needed because arc is submerged and the molten metal is separated from the air by the molten slag and granular flux. Direct-current electrode positive is most often used. However, at very high welding currents, AC is preferred in order to minimize arc blow (Kou 2003).

The knowledge of how welding process parameters affect weld bead geometry is important because it can be applied in automatic and semiautomatic control of arc welding processes where optimal selection of input parameters is required for high productivity and cost effectiveness (Shen et al 2012). The welding current direction also affects the weld bead profile. The current may be direct with the electrode positive (reverse polarity), electrode negative (straight polarity), or alternating (ASM 1993). As reported by various researchers, electrode positive polarity produces wider beads usually with more penetration depth and electrode negative polarity yields narrower beads with low penetration (Chandel 1987; Yang et al 1993).

Mechanical properties of a welded joint are dictated mainly by weld bead contour, HAZ area, precipitation process and heat input during welding (Lancaster 1993). Base metal in the vicinity of deposited weld metal undergoes a considerable change metallurgically and mechanically due to weld thermal cycle. Size of this heat affected zone (HAZ) depends on the heat input and is to be predicted for better analysis and understanding of the characteristics of HAZ affecting the microstructure and properties of the welded steel (Gunaraj \& Murugan 1999a).

\section{Literature survey}

Extensive work has been done by many researchers in the field of submerged arc welding and various aspects of this fusion joining process have been discussed. Some of these researches have been highlighted.

Pandey et al (1994) showed in their work that welding current and voltage have an appreciable influence on element transfer, as well as on weld composition. Weldment properties such as strength, toughness and solidification cracking behaviour are affected by chemical composition of the weld. Chandel et al (1997) through their research paper presented theoretical predictions of the effect of current, electrode polarity, electrode diameter and electrode extension on the melting rate, bead height, bead width and weld penetration, in submerged-arc welding. Khallaf et al (1997) described cracking behaviour during the submerged arc welding of medium carbon steel plates and found that the cracking susceptibility increases with an increase in the welding current and decreases with an increase in the welding speed or the electrode wire feed rate. It also increases with increases in the plate rolling reduction ratio and with decrease in the plate thickness.

Gunaraj \& Murugan (1999a) studied the effect of controllable process variables on the heat input and the area of the heat-affected zone (HAZ) for bead-on-plate and bead-on joint welding using mathematical models developed for the submerged arc welding of pipes. A comparative study of the area of the heat-effected zone between bead-on-plate and bead-on-joint welding was then carried out. Gunaraj \& Murugan (1999b), Murugan \& Gunaraj (2005) again addressed the main problem faced in the manufacture of pipes by the SAW process regarding the selection of the optimum combination of input variables for achieving the required qualities of weld. They suggested the solution by the development of mathematical models through effective and strategic planning and the execution of experiments by RSM. Tušek (2000) worked on mathematical modelling of melting rate in twin-wire welding for the first time and found his models were very 
accurate practically. A multi wire SAW process was modelled by Wen et al (2001) using a general purpose finite element package for thick wall line pipes. It was shown that the geometric distortion and residual stresses and strains can be minimized through process optimization.

Pandey (2004) proposed a relationship between welding current and direct SAW process parameters using two level half factorial design. Interactive effects of direct parameters were also studied. The study performed by Karaoğlu \& Seçgin (2008) focuses on the sensitivity analysis of parameters and fine tuning requirements of the parameters for optimum weld bead geometry. Changeable process parameters such as welding current, welding voltage and welding speed are used as design variables. Effects of all three design parameters on the bead width and bead height show that even small changes in these parameters play an important role in the quality of welding operation. The results also reveal that the penetration is almost non-sensitive to the variations in voltage and speed. Dhas \& Kumanan (2011) used Taguchi's design of experiments and regression analysis to establish input-output relationships of the process. By this relationship, an attempt was made to minimize weld bead width, a good indicator of bead geometry, using optimization procedures based on the genetic algorithm (GA) and particle swarm optimization (PSO) algorithm to determine optimal weld parameters.

Ghosh et al (2011a) addressed the issue associated with the uncertainties involved with the heat affected zone (HAZ) in and around the weldment produced by SAW process. The most intriguing issue is about HAZ softening that imparts some uncertainties in the welded quality. It increases the probability of fatigue failures at the weakest zones caused by the heating and cooling cycle of the weld zone. They assessed the heat affected zone of submerged arc welding of structural steel plates through the analysis of the grain structure by means of digital image processing techniques. It was concluded that the grains are predominantly of smaller variety and the counts for larger grain are almost negligible. The absence of larger size grains in the image vouch for the soundness of the weld in comparison to the competing welding methodologies of structural steel plates. Ghosh et al $(2011 \mathrm{~b}$, c) used graphical technique to predict submerged arc welding yield parameters and studied the effect of main factors, viz. current, wire feed rate, travel speed and stick out and the interactions among the main factors on the welding bead parameters. The interactions depicted the level of confounded character of the main factors with respect to the significant yield parameters of the process.

A series of measurements was carried out by Shen et al (2012) on specimens of submerged arc welded plates of ASTM A709 Grade 50 steel. The bead reinforcement, bead width, penetration depth, HAZ size, deposition area and penetration area increased with increasing heat input but the bead contact angle decreased with it. The electrode melting efficiency increased initially and then decreased with increasing heat input but the plate melting efficiency and percentage dilution changed only slightly with it. Cooling time exhibited a very good linear relationship with the total nugget area, heat transfer boundary length, and nugget parameter.

\section{Motivation for the present work}

It is clear from the literature survey that a lot of work has been done in past years regarding the modelling of bead geometry with respect to SAW parameters. Various statistical and modelling techniques have used by different authors. HAZ, which is a critical zone in any weldment, has been only modelled by Gunaraj and Murugan in 1999. They correlated the HAZ area with the heat input and other welding parameters and comparison was done between HAZ produced in bead on plate welds and pipe joint welds. It was concluded that for the same heat input, area of the HAZ is greater on the plate than on the joint. 
No studies in the past, however, been carried out to find the direct and interactive effect of electrode polarity on the size of heat affected zone and heat input to the weld pool for submerged arc welding. In the present work, an attempt is made to fill this gap by modelling the size of HAZ for electrode positive as well as electrode negative polarity by using factorial design technique. The effect of heat input on the percentage dilution and heat affected zone has also been studied.

\section{Scheme of investigation}

\subsection{Identification of parameters and determination of working limits}

Predominant parameters that had greater influence on welding quality were identified as wire feed rate (WFR), open circuit voltage (OCV), welding speed (WS) and electrode polarity (PO) were selected as welding parameters since they can be varied independently (Om \& Pandey 2010). The working limits of selected parameters were finalized on the basis of a large number of trial runs. Minimum and maximum levels of each parameter were decided by inspecting the resulting bead on plate carefully so that it was free of any visible welding defect like surface porosity, undercut, overlap, excessive convexity and cracks, etc. and it had smooth and uniform appearance throughout the length. The high and low levels of the parameters were coded as +1 and -1 , respectively. The actual values of parameters corresponding to the coded values are given in table 1.

Further coded value for any intermediate actual value of given variable can be calculated from the following relationship

$$
X=\left[2 x-\left(x_{\max }+x_{\min }\right)\right] /\left(x_{\max }-x_{\min }\right),
$$

where $X$ is the required coded value of a variable, $x$ is any actual value of variable lying between $x_{\min }$ to $x_{\max }, x_{\min }$ and $x_{\max }$, are the actual values of variable at low and high levels, respectively (Murugan \& Parmar 1993; Pandey 2004).

\subsection{Developing the design matrix}

Statistical design of experiment is the process of planning the experiment so that the appropriate data that can be analysed by statistical methods will be collected, resulting in valid and objective conclusions (Montgomery 2001). This approach is necessary if we wish to draw any meaningful conclusions from the data. Factorial designs are the most efficient experimental design methods since all possible combinations of the levels of the factors are investigated in each trial of the experiment (Anderson \& McLean 1974). The number of trials in a factorial

Table 1. Parameters and their values at two levels.

\begin{tabular}{lccccc}
\hline Process parameter & Units & Notation & Type of parameter & Low level $(-1)$ & High level (+1) \\
\hline $\begin{array}{l}\text { Open circuit } \\
\quad \text { voltage }\end{array}$ & Volts & OCV & Numeric & 33 & 42 \\
Wire feed & $\mathrm{mm} / \mathrm{sec}$ & WFR & Numeric & 16 & 28 \\
Welding speed & $\mathrm{mm} / \mathrm{sec}$ & WS & Numeric & 5.5 & 10 \\
Polarity & & PO & Categorical & $\begin{array}{c}\text { Electrode } \\
\text { negative (EN) }\end{array}$ & $\begin{array}{c}\text { Electrode } \\
\text { positive (EP) }\end{array}$ \\
\hline
\end{tabular}


experiment increase considerably with increase in the number of factors (Adler 1975). Fractional factorial experiments are important alternatives to complete factorial experiments when budgetary, time, or experimental constraints preclude the execution of complete factorial experiments (Mason et al 2003). In this work, a half fractional factorial design was adopted to cut down the number of runs needed for full factorial design.

The design matrix, considering four independent welding parameters as mentioned in section 4.1, was developed as per $2^{k-1}$ fractional factorial design to conduct a total of eight runs $\left(2^{4-1}=8\right)$. Parameters WFR, OCV, WS and PO have been represented by the numbers 1,2 , 3 and 4, respectively in the present paper. The main effect of electrode polarity (PO) was confounded with the other three parameters (WFR, OCV, WS) interaction effect. The forth column of the matrix was generated using the confounding pattern. The signs under the column 1, 2, 3 were arranged in standard Yate's order, while those under the column 4 were obtained by selecting a generating relation $4=123$. This means, defining contrast for the design was $\mathrm{I}=1234$. Three parameters and higher order interactions were assumed to be negligible; the half fractional factorial design of eight runs provided eight estimates for the effect of four welding parameters on a particular response. Out of these estimates, one estimate was for the mean effect of all the parameters on response, four estimates for the main effects and the remaining three confounded estimates for two parameter interactions (Adler 1975; Pandey 2004). Design matrix for coefficients and confounding patterns has been shown in table 2.

\subsection{Experimental procedure}

A direct current constant voltage power source and mechanized submerged arc welding equipment with a current capacity of 600 amperes was used for the experimentation. The equipment could be used for an open circuit voltage range of 12-48 volts. A 'single bead on plate' technique was used to deposit beads on $250 \mathrm{~mm} \times 75 \mathrm{~mm} \times 10 \mathrm{~mm}$ mild steel plates. A general purpose agglomerated acidic flux (AWS SFA A-5.17) with a basicity index of 0.6 along with a compatible mild steel single wire electrode of $3.15 \mathrm{~mm}$ diameter was used. The plates were cleaned chemically and mechanically to remove rusting and possible sources of hydrogen such as grease and oil, etc. The bead was deposited along the longitudinal centre line of each plate carefully so that the heat distribution on both sides of bead remained same. The plates were then left to cool at room temperature.

Table 2. Design matrix for calculating coefficients.

\begin{tabular}{|c|c|c|c|c|c|c|c|}
\hline $\begin{array}{l}\text { Regression } \\
\text { coefficient }\end{array}$ & WFR & $\mathrm{OCV}$ & WS & $\mathrm{PO}$ & $\begin{array}{c}\mathrm{WFR} * \mathrm{OCV}= \\
\mathrm{WS} * \mathrm{PO}\end{array}$ & $\begin{array}{c}\mathrm{WFR} * \mathrm{WS}= \\
\mathrm{OCV} * \mathrm{PO}\end{array}$ & $\begin{array}{l}\mathrm{WFR} * \mathrm{PO}= \\
\mathrm{OCV} * \mathrm{WS}\end{array}$ \\
\hline $\mathrm{b}_{0}$ & $\begin{array}{c}1 \\
b_{1}\end{array}$ & $\begin{array}{c}2 \\
b_{2}\end{array}$ & $\begin{array}{c}3 \\
b_{3}\end{array}$ & $\begin{array}{c}4 \\
\mathrm{~b}_{4}\end{array}$ & $\begin{array}{c}12=34 \\
b_{5}\end{array}$ & $\begin{array}{c}13=24 \\
b_{6}\end{array}$ & $\begin{array}{c}14=23 \\
b_{7}\end{array}$ \\
\hline 1 & 1 & 1 & 1 & 1 & 1 & 1 & 1 \\
\hline 1 & -1 & 1 & 1 & -1 & -1 & -1 & 1 \\
\hline 1 & 1 & -1 & 1 & -1 & -1 & 1 & -1 \\
\hline 1 & -1 & -1 & 1 & 1 & 1 & -1 & -1 \\
\hline 1 & 1 & 1 & -1 & -1 & 1 & -1 & -1 \\
\hline 1 & -1 & 1 & -1 & 1 & -1 & 1 & -1 \\
\hline 1 & 1 & -1 & -1 & 1 & -1 & -1 & 1 \\
\hline 1 & -1 & -1 & -1 & -1 & 1 & 1 & 1 \\
\hline
\end{tabular}




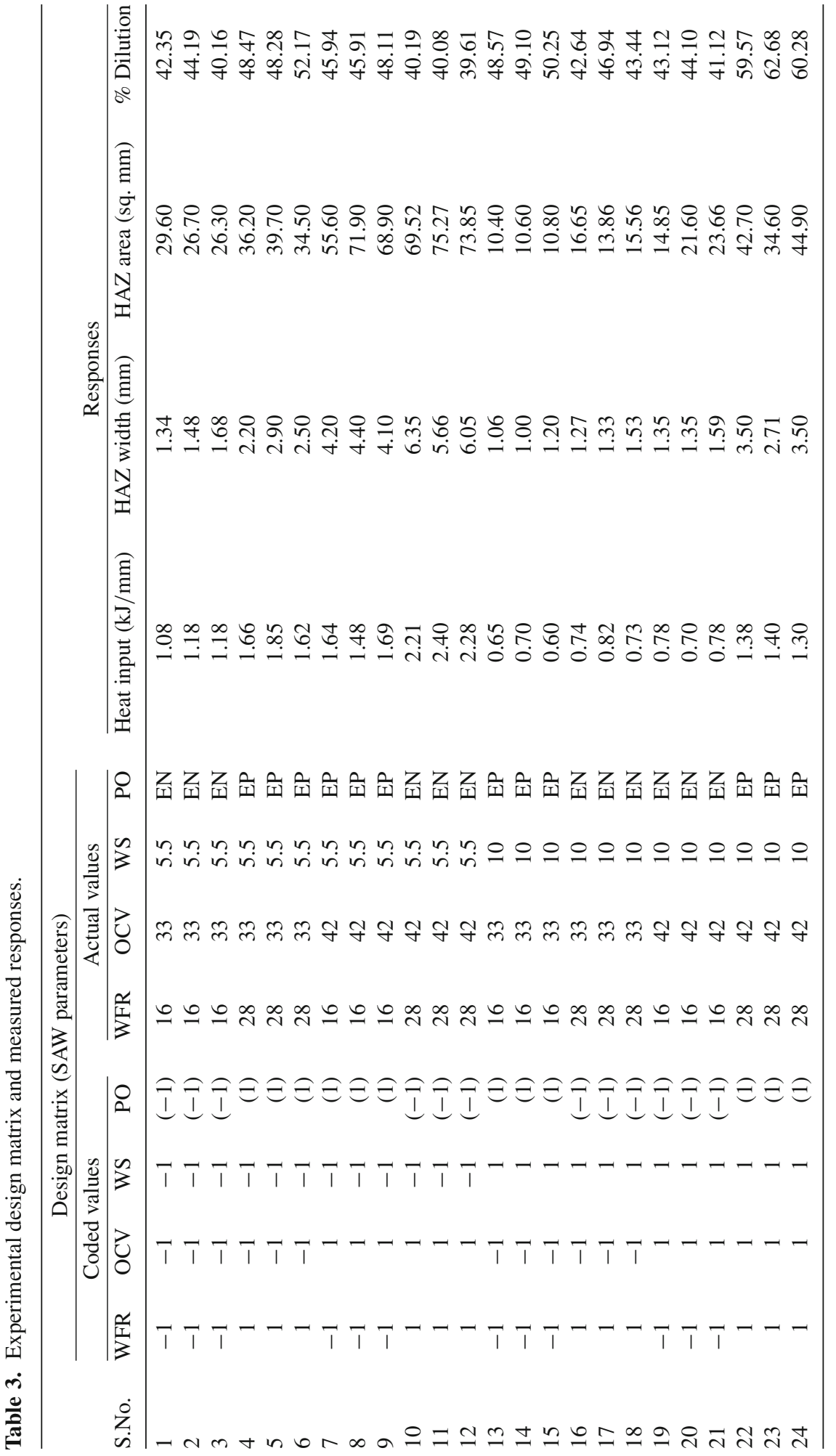


Three replicates for each of eight experimental runs (total runs $8 \times 3=24$ ) were conducted as per the design matrix. The nozzle to plate distance was kept constant throughout the experiment at $30 \mathrm{~mm}$. These runs were performed randomly as the randomization protects against unknown biases, including any unanticipated or unobservable 'break-in' effects due to greater or lesser care in conducting the experiment (Mason et al 2003).

\subsection{Recording of responses}

Welding current and welding voltage were recorded during welding for the given set of parameters for each experimental run. After cooling at room temperature each plate was cut at the centre transverse to the welding direction in order to obtain the specimen of about $10 \mathrm{~mm}$ thickness. The sized specimens were molded with Bakelite and then polished using fine grade emery papers. Molded and polished specimens were then etched with $2 \%$ Nital solution in order to reveal different zones of deposited weld bead. Well etched specimens were then scanned using high resolution scanner and bead profiles and area of HAZ were measured using digital measuring tools.

\subsection{Development of model}

Table 3 shows the experimental design matrix and measured responses. The functional relationship $R=f(W F R, O C V, W S, P O)$ was considered, where $\mathrm{R}$ is one of the responses. This relation can be expressed as shown in eqn. (2).

$$
\begin{aligned}
R= & b_{0}+b_{1} W F R+b_{2} O C V+b_{3} W S+b_{4} P O+b_{12} W F R * O C V \\
& +b_{13} W F R * W S+b_{14} W F R * P O+b_{23} O C V * W S+b_{24} O C V * P O \\
& +b_{34} P O * W S
\end{aligned}
$$

Table 4. ANOVA for HAZ width.

\begin{tabular}{lrrrrrr}
\hline Source & SS & DF & MS & F-VALUE & P-VALUE & \% CONTR \\
\hline Model & 5.30 & 6 & 0.88 & 152.40 & $<0.0001$ & \\
WFR & 0.84 & 1 & 0.84 & 144.26 & $<0.0001$ & 15.78 \\
OCV & 2.30 & 1 & 2.30 & 396.26 & $<0.0001$ & 43.34 \\
WS & 1.68 & 1 & 1.68 & 290.26 & $<0.0001$ & 31.74 \\
PO & 0.07 & 1 & 0.07 & 12.55 & 0.0025 & 1.37 \\
WFR*OCV & 0.09 & 1 & 0.09 & 16.20 & 0.0009 & 1.77 \\
WFR*PO & 0.32 & 1 & 0.32 & 54.87 & $<0.0001$ & 6.00 \\
Residual & 0.10 & 17 & 0.01 & & & \\
Lack of fit & 0.00 & 1 & 0.00 & 0.05 & 0.8203 & \\
Pure error & 0.10 & 16 & 0.01 & & & \\
Cor total & 5.40 & 23 & & & & \\
Std. Dev. & 0.076 & & & & Adj -R ${ }^{2}$ & 0.982 \\
Mean & 1.566 & & & & Sred- R R $^{2}$ & 0.964 \\
C.V. \% & 4.861 & & & & & 34.328 \\
Press & 0.196 & & & & & \\
\hline
\end{tabular}


Table 5. ANOVA for HAZ area.

\begin{tabular}{lrrrrrr}
\hline Source & \multicolumn{1}{c}{ SS } & DF & \multicolumn{1}{c}{ MS } & F-VALUE & P-VALUE & \% CONTR \\
\hline Model & 10843.83 & 5 & 2168.77 & 98.17 & $<0.0001$ & \\
WFR & 665.71 & 1 & 665.71 & 30.13 & $<0.0001$ & 6.14 \\
OCV & 4441.22 & 1 & 4441.22 & 201.04 & $<0.0001$ & 40.96 \\
WS & 5041.94 & 1 & 5041.94 & 228.23 & $<0.0001$ & 46.50 \\
PO & 118.73 & 1 & 118.73 & 5.37 & 0.0324 & 1.09 \\
WFR*PO & 576.24 & 1 & 576.24 & 26.08 & $<0.0001$ & 5.31 \\
Residual & 397.65 & 18 & 22.09 & & & \\
Lack of fit & 103.28 & 2 & 51.64 & 2.81 & 0.0902 & \\
Pure error & 294.37 & 16 & 18.40 & & & \\
Cor total & 11241.48 & 23 & & & & \\
Std. Dev. & 4.700 & & & & Adj -R & \\
Mean & 36.176 & & & & Pred- R $\mathrm{R}^{2}$ & 0.955 \\
C.V. \% & 12.993 & & & & & 0.937 \\
Press & 706.929 & & & & & \\
\hline
\end{tabular}

According to confounding pattern, $12=34,13=24$ and $14=23$, shown in table 2 , the above relation can be modified by incorporating the confounding parameters as given in eqn. (3).

$$
\begin{aligned}
R= & b_{0}+b_{1} W F R+b_{2} O C V+b_{3} W S+b_{4} P O+b_{5} W F R * O C V \\
& +b_{6} W F R * W S+b_{7} W F R * P O
\end{aligned}
$$

where, $b_{5}=\left(b_{12}+b_{34}\right), b_{6}=\left(b_{13}+b_{24}\right), \& b_{7}=\left(b_{14}+b_{23}\right)$.

4.5a Checking the adequacy of developed model: The significance of the model was tested by using Analysis of Variance (ANOVA) technique. The result of ANOVA for responses is shown in tables 4, 5, 6 and 7. These tables show details of sum of squares (SS), degrees of freedom

\begin{tabular}{|c|c|c|c|c|c|c|}
\hline Source & SS & $\mathrm{DF}$ & MS & F-VALUE & P-VALUE & $\%$ CONTR \\
\hline Model & 6209089 & 7 & 887013 & 156.44 & $<0.0001$ & \\
\hline WFR & 1322022 & 1 & 1322022 & 233.17 & $<0.0001$ & 21.29 \\
\hline $\mathrm{OCV}$ & 1030372 & 1 & 1030372 & 181.73 & $<0.0001$ & 16.59 \\
\hline WS & 3543484 & 1 & 3543484 & 624.97 & $<0.0001$ & 57.07 \\
\hline PO & 43493 & 1 & 43493 & 7.67 & 0.0137 & 0.70 \\
\hline $\mathrm{AB}$ & 130732 & 1 & 130732 & 23.06 & 0.0002 & 2.11 \\
\hline $\mathrm{AC}$ & 101792 & 1 & 101792 & 17.95 & 0.0006 & 1.64 \\
\hline $\mathrm{AD}$ & 37195 & 1 & 37195 & 6.56 & 0.0209 & 0.60 \\
\hline Pure error & 90718 & 16 & 5670 & & & \\
\hline Cor total & 6299807 & 23 & & & & 100 \\
\hline Std. Dev. & 75.29839 & & & & $\mathrm{R}^{2}$ & 0.986 \\
\hline Mean & 1220.246 & & & & Adj $-R^{2}$ & 0.979 \\
\hline C.V. $\%$ & 6.170754 & & & & Pred- $\mathrm{R}^{2}$ & 0.968 \\
\hline Peess & 204114.5 & & & & $\mathrm{~S} / \mathrm{N}$ ratio & 36.048 \\
\hline
\end{tabular}

Table 6. ANOVA for heat input. 
Table 7. ANOVA for percentage dilution.

\begin{tabular}{|c|c|c|c|c|c|c|}
\hline Source & SS & $\mathrm{DF}$ & MS & F-VALUE & P-VALUE & $\%$ CONTR \\
\hline Model & 903.95 & 7 & 129.14 & 48.08 & $<0.0001$ & \\
\hline WFR & 71.54 & 1 & 71.54 & 26.64 & $<0.0001$ & 7.91 \\
\hline $\mathrm{OCV}$ & 8.33 & 1 & 8.33 & 3.10 & 0.0972 & 0.92 \\
\hline WS & 132.44 & 1 & 132.44 & 49.31 & $<0.0001$ & 14.65 \\
\hline PO & 517.08 & 1 & 517.08 & 192.53 & $<0.0001$ & 57.20 \\
\hline $\mathrm{WFR} * \mathrm{OCV}$ & 29.92 & 1 & 29.92 & 11.14 & 0.0042 & 3.31 \\
\hline WFR $* W S$ & 57.47 & 1 & 57.47 & 21.40 & 0.0003 & 6.36 \\
\hline WFR $* \mathrm{PO}$ & 87.16 & 1 & 87.16 & 32.45 & $<0.0001$ & 9.64 \\
\hline Pure error & 42.97 & 16 & 2.69 & & & \\
\hline Cor total & 946.92 & 23 & & & & 100 \\
\hline Std. Dev. & 1.639 & & & & $\mathrm{R}^{2}$ & 0.955 \\
\hline Mean & 46.970 & & & & Adj $-R^{2}$ & 0.935 \\
\hline C.V. $\%$ & 3.489 & & & & Pred- $\mathrm{R}^{2}$ & 0.898 \\
\hline Press & 96.687 & & & & $\mathrm{~S} / \mathrm{N}$ ratio & 22.076 \\
\hline
\end{tabular}

(DF), mean square (MS), F-Ratio (F-VALUE) and Probability of larger F-value (P-VALUE) along with the percentage contribution (CONTR\%) of each of the factors and their interactions in the model (Fnides et al 2011). The F value in the ANOVA table, also known as the ratio of variances, is the ratio of model mean square (MS) to the appropriate error mean square. Larger

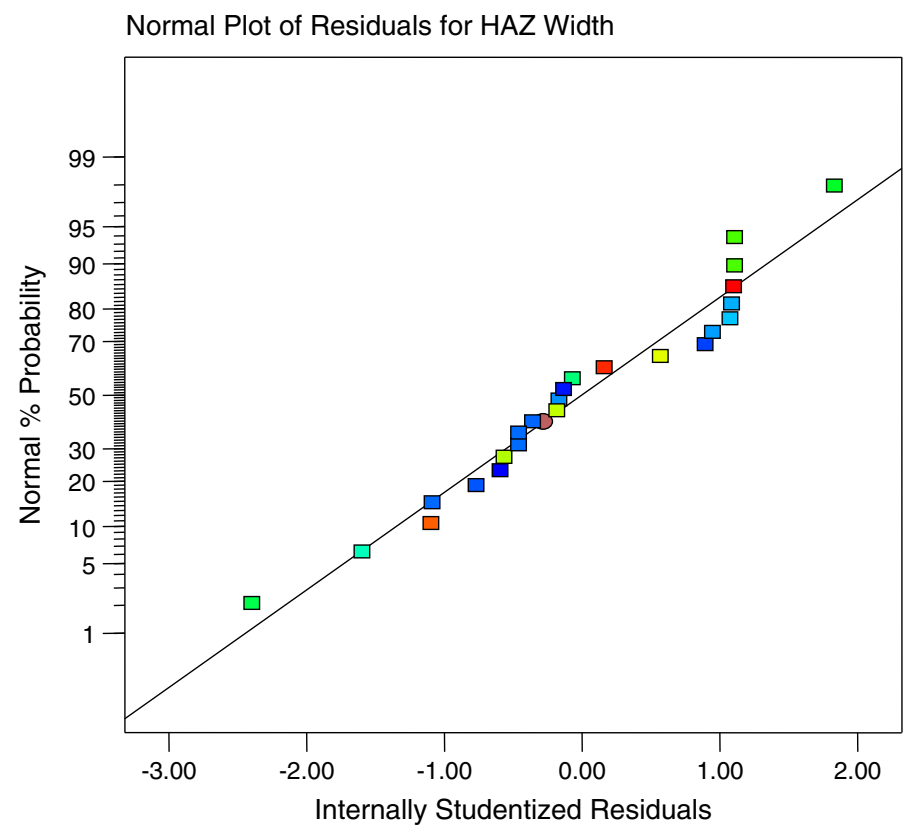

Figure 1. Normal probability plot of the studentized residuals to check normality of residuals for HAZ width. 
F-values show that the variance contributed by the model is significantly larger than random error. If the $\mathrm{F}$ ratio lies near the tail of the F-distribution then the probability of a larger $\mathrm{F}$ is small and the variance ratio is judged to be significant. Usually, a probability value less than 0.05 is considered significant at $95 \%$ confidence level, thus justifying the use of the assumed polynomial. Coefficient of multiple determination $\mathrm{R}^{2}$ and adjusted $\mathrm{R}^{2}$ are the measures of the amount of reduction in the variability of particular response. For a model to be adequate, $\mathrm{R}^{2}$ and adjusted $\mathrm{R}^{2}$ values must approach unity and be close to each other. If they differ considerably, there is a good chance that non-significant terms have been included in the model (Montgomery 2001).

4.5b Significance of coefficients of the model: It is quite important to determine whether the coefficients are statistically significant or not. The statistical significance of the coefficients was tested by applying the ' $t$ ' test. Coefficients having ' $t$ ' values less than or equal to the listed ' $t$ ' value from tables at $95 \%$ confidence level, are considered insignificant and can be dropped along with the responses with which they are associated without affecting much the accuracy of the proposed model (Gunaraj \& Murugan 1999b; Pandey 2004). Only the significant coefficients and associated parameters were considered in the developed mathematical model. The model should consist of the factors and interactions that are significant, plus any terms that are needed to maintain hierarchy. For the present 2-level factorial design, the half-normal probability plots and Pareto charts were used to choose an appropriate model for each response. Normal probability plots and predicted vs. actual responses plots are shown in figures 1, 2, 3, 4, 5, 6, 7 and 8 . Modelling software 'Design Expert' was used for analysis of variance.

Normal Plot of Residuals for HAZ Area

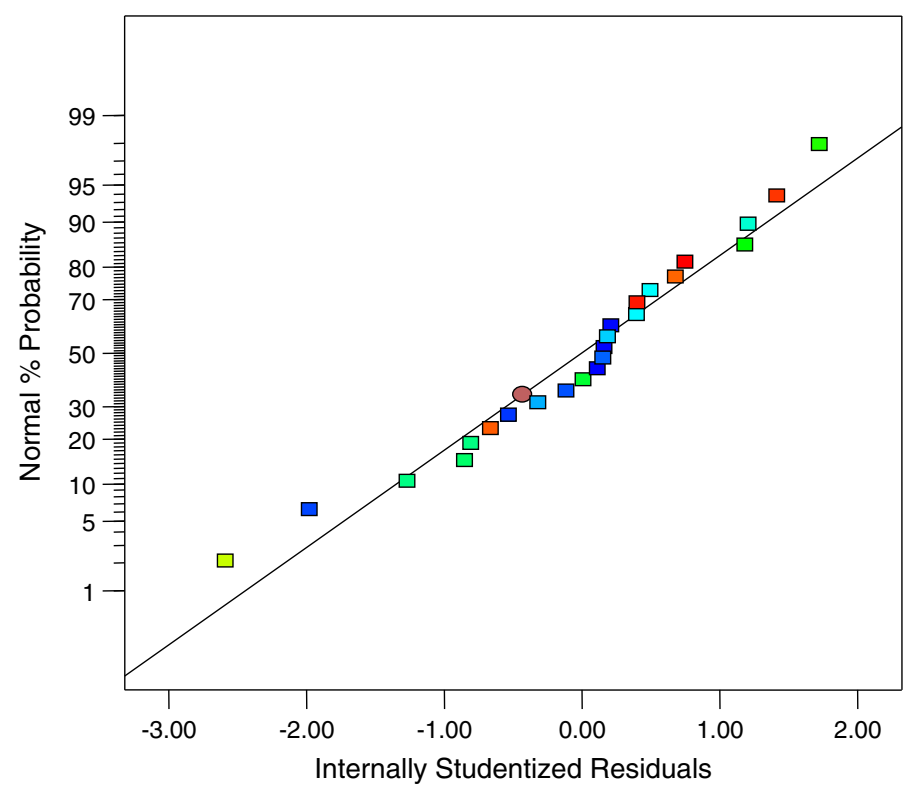

Figure 2. Normal probability plot of the studentized residuals to check normality of residuals for HAZ area. 


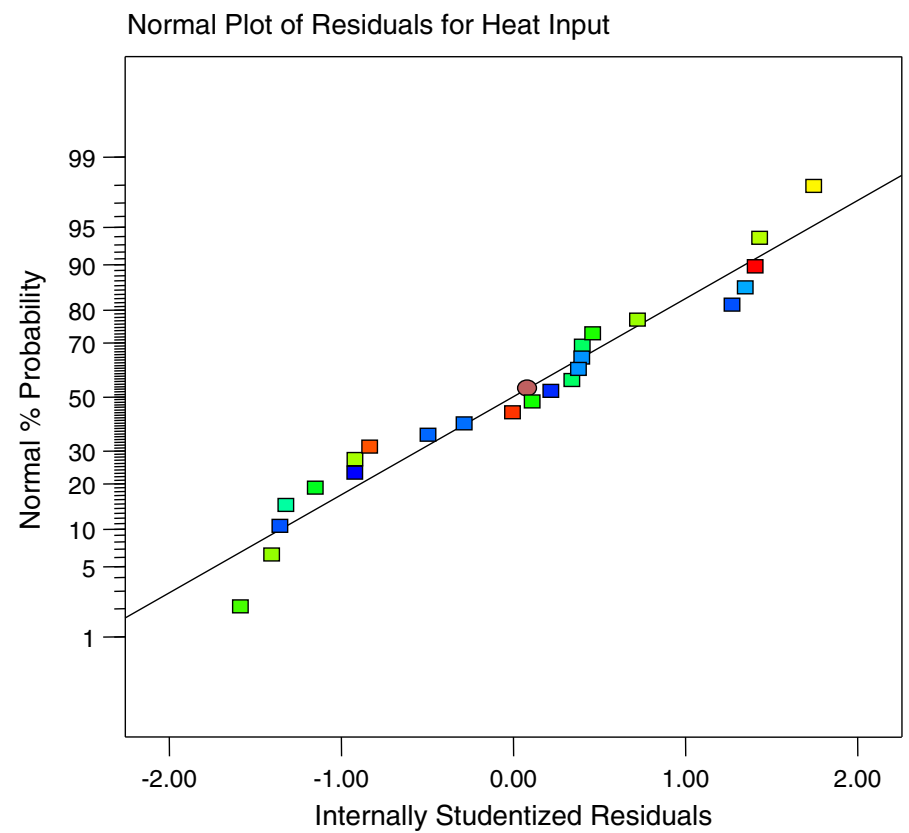

Figure 3. Normal probability plot of the studentized residuals to check normality of residuals for heat input.

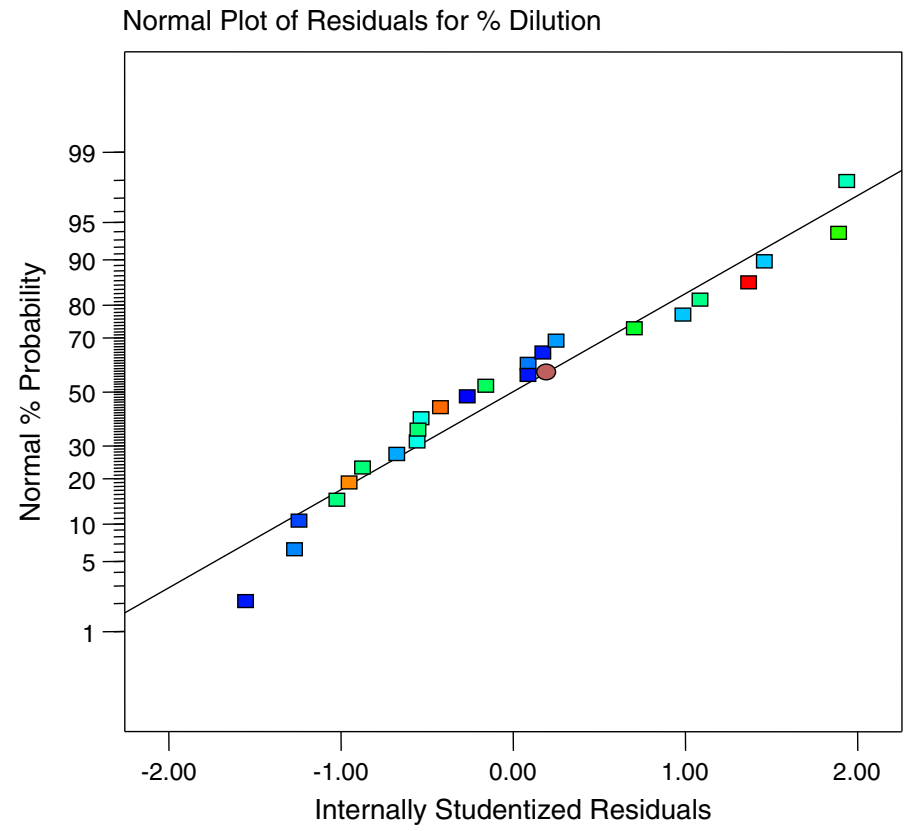

Figure 4. Normal probability plot of the studentized residuals to check normality of residuals for \%dilution. 


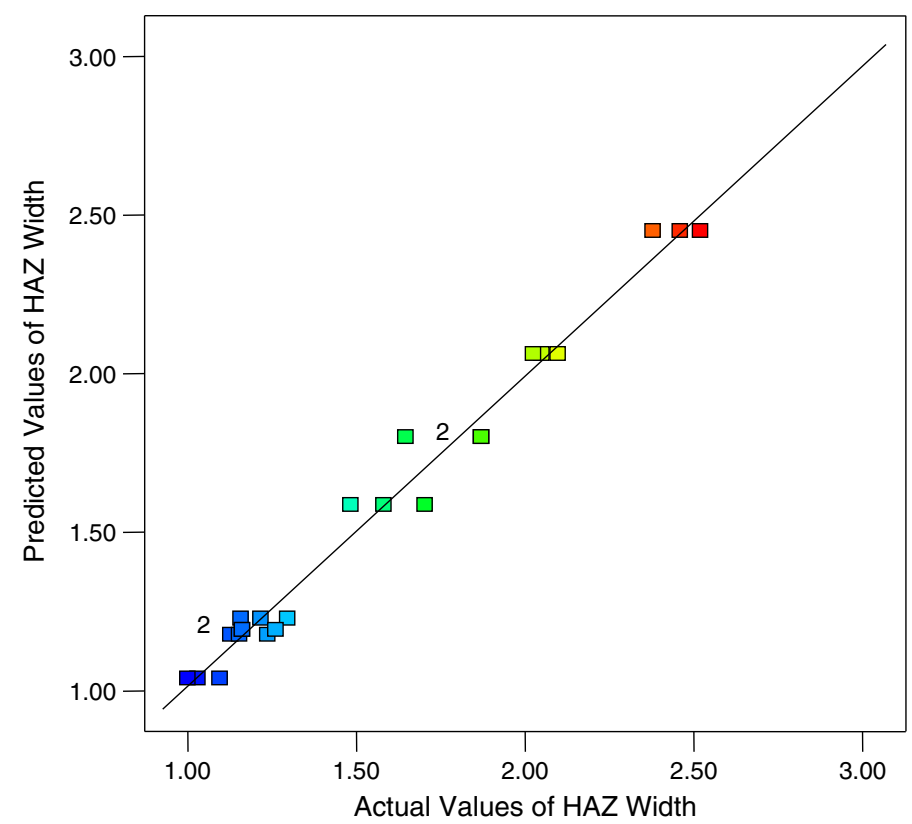

Figure 5. Predicted HAZ width vs. actual HAZ width.

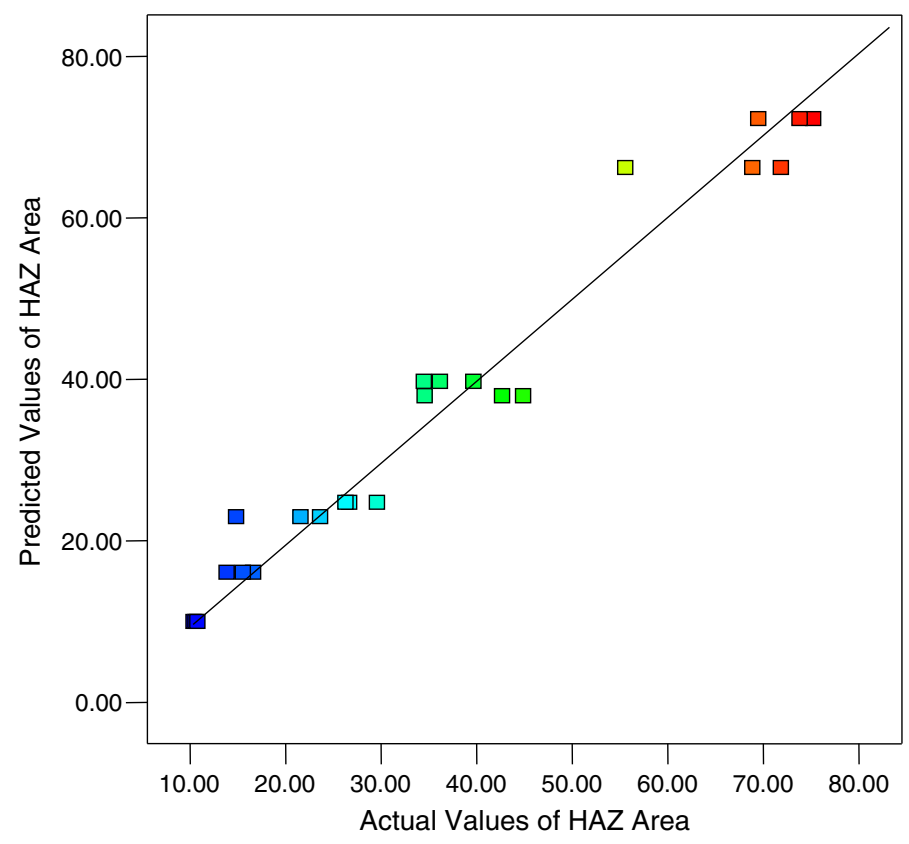

Figure 6. Predicted HAZ area vs. actual HAZ area. 


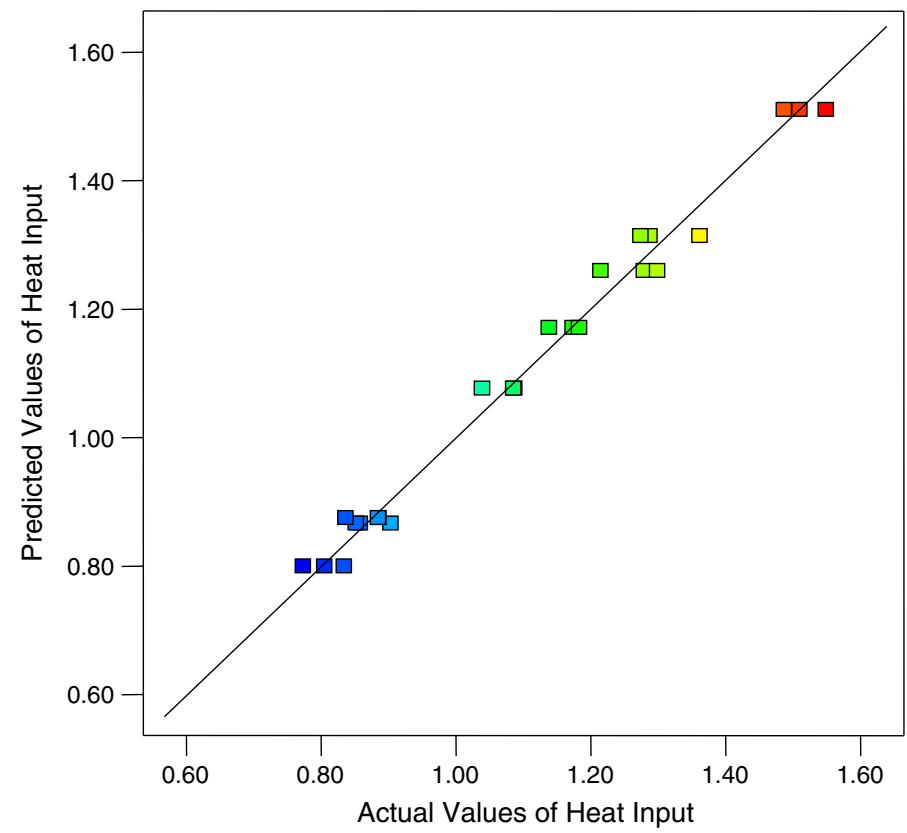

Figure 7. Predicted heat input vs. actual heat input.

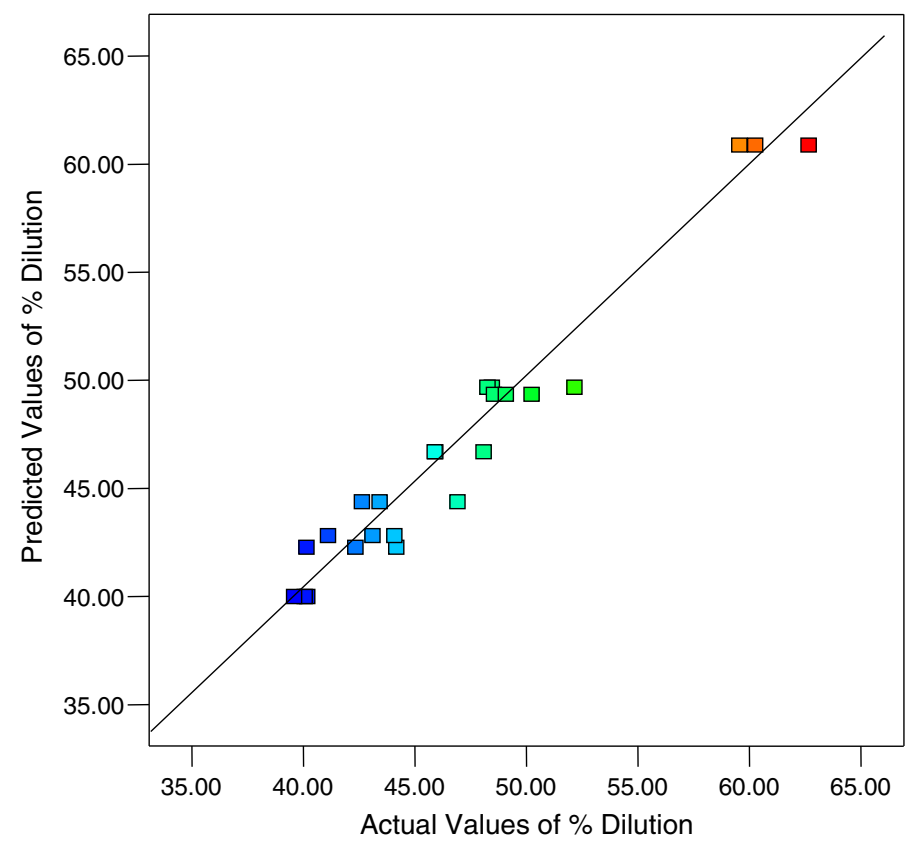

Figure 8. Predicted percentage dilution vs. actual percentage dilution. 


\subsection{Final models}

After carefully analyzing the measured responses by statistical techniques, final models comprised of significant factors only were developed as follows;

Final equation in terms of coded factors:

$$
\begin{aligned}
H A Z \text { Width }= & {[1.57+0.19 * W F R+0.31 * O C V-0.26 * W S+0.055 * P O} \\
& +0.063 * W F R * O C V-0.12 * W F R * P O]^{2}
\end{aligned}
$$

$H A Z$ Area $=36.18+5.27 * W F R+13.60 * O C V-14.49 * W S+2.22 * P O-4.90 * W F R * P O$

$$
\begin{aligned}
\text { Heat Input }= & 1220.25+234.70 * W F R+207.20 * O C V-384.25 * W S \\
& +42.57 * P O+73.80 * W F R * O C V-65.13 * W F R * W S \\
& -39.37 * W F R * P O
\end{aligned}
$$

$$
\begin{aligned}
\% \text { Dilution }= & 46.97+1.73 * W F R+0.59 * O C V+2.35 * W S \\
& +4.64 * P O+1.12 * W F R * O C V+1.55 * W F R * W S \\
& +1.91 * W F R * P O .
\end{aligned}
$$

Final equation in terms of actual factors with electrode posive polarity:

$$
\begin{aligned}
\text { HAZ Width }= & {[1.604-0.075 * W F R+0.018 * O C V-0.118 * W S} \\
& +0.002316 * W F R * O C V]^{2} \\
\text { HAZ Area }= & -26.381+0.061 * W F R+3.023 * O C V-6.442 * W S \\
\text { Heat Input }= & 1576.078-32.565 * W F R-14.093 * O C V-64.646 * W S \\
& +2.734 * W F R * O C V-4.82 * W F R * W S \\
\% \text { Dilution }= & 78.951-1.834 * W F R-0.778 * O C V-1.478 * W S \\
& +0.041 * W F R * O C V+0.115 * W F R * W S .
\end{aligned}
$$

Final equation in terms of actual factors with electrode negative polarity:

$$
\begin{aligned}
\text { HAZ Width }= & {[0.649-0.037 * W F R+0.018 * O C V-0.118 * W S} \\
& +0.002316 * W F R * O C V]^{2} \\
H A Z \text { Area }= & -66.763+1.694 * W F R+3.023 * O C V-6.442 * W S \\
\text { Heat Input }= & 1202.244-19.442 * W F R-14.093 * O C V-64.646 * W S \\
& +2.733 * W F R * O C V-4.824 * W F R * W S
\end{aligned}
$$




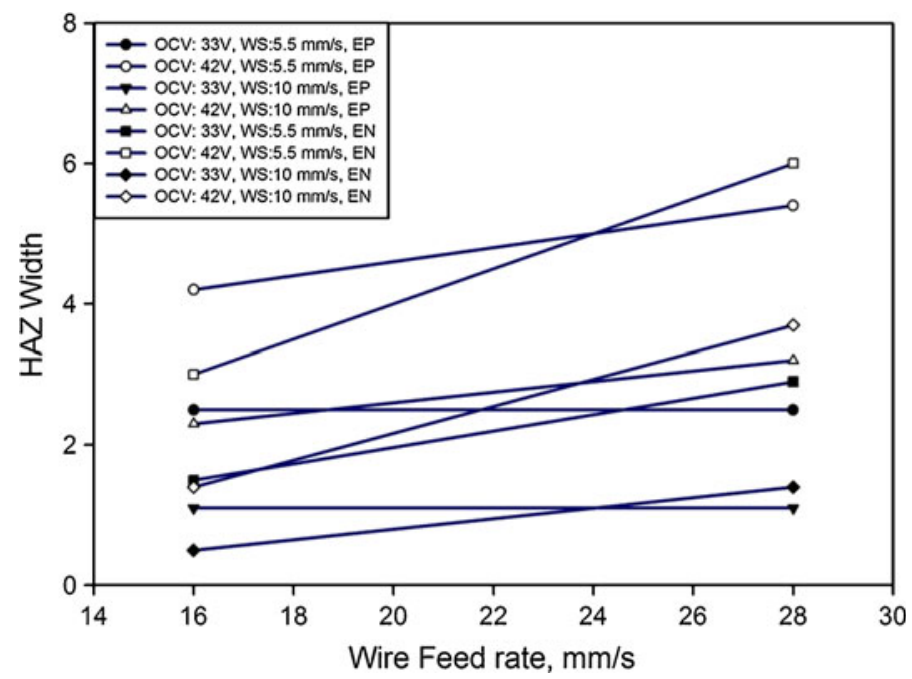

Figure 9. Interaction effects of process parameters on HAZ width.

$$
\begin{aligned}
\% \text { Dilution }= & 83.643-2.469 * W F R-0.779 * O C V-1.478 * W S \\
& +0.041 * W F R * O C V+0.115 * W F R * W S .
\end{aligned}
$$

\section{Results and discussions}

Above mentioned mathematical models in terms of coded factors (eq. 4-7) may be used to predict the responses like HAZ width, HAZ area, heat input per unit length and \% dilution by substituting parameter values in the coded form. Equation 8-11 represent models in terms of

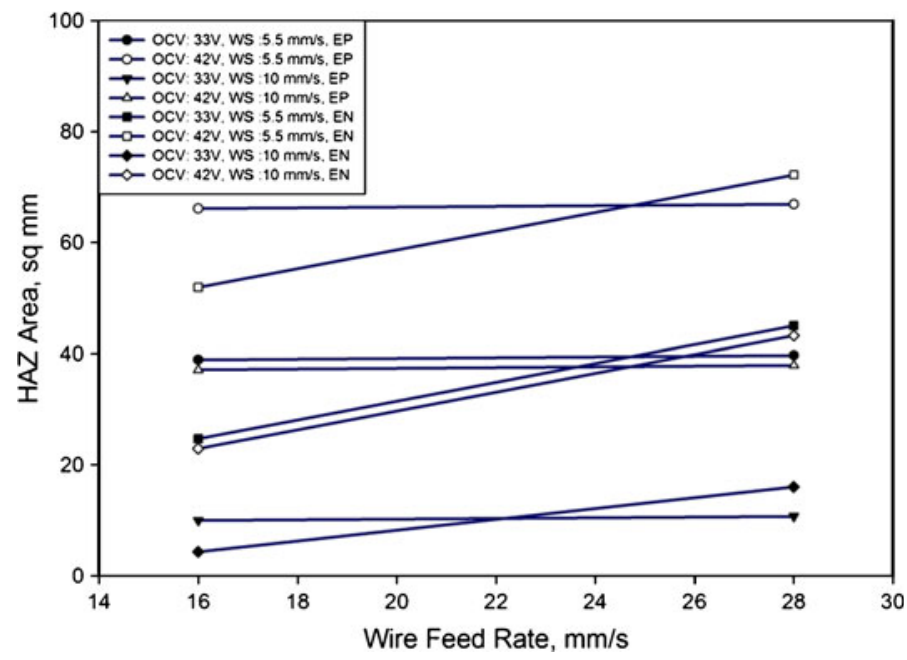

Figure 10. Interaction effects of process parameters on $\mathrm{HAZ}$ area. 


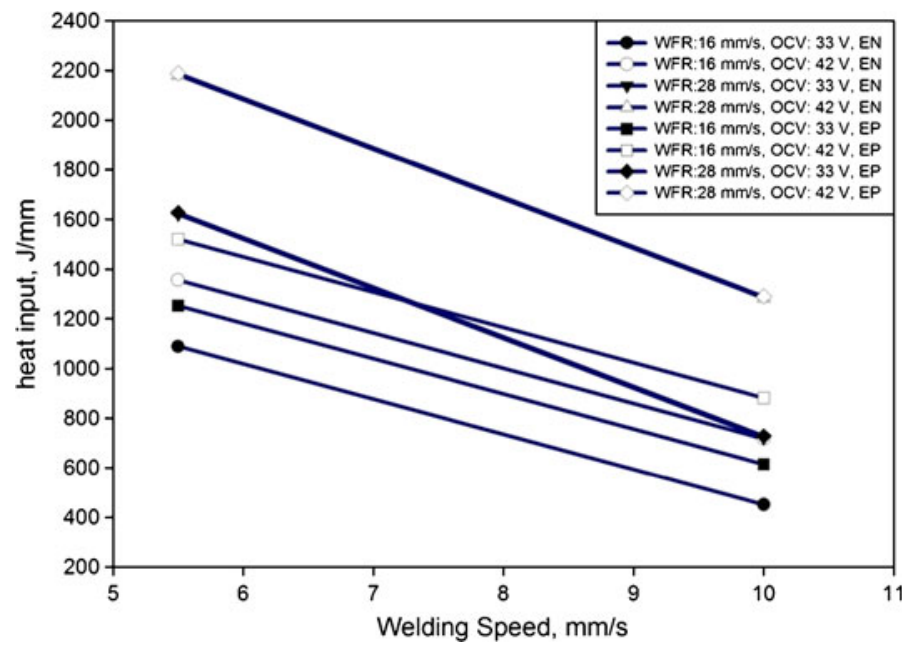

Figure 11. Interaction effects of process parameters on heat input.

actual factors for electrode positive polarity and eqn. 12-15 stand for models in terms of actual factors for electrode negative polarity and direct values can be calculated by putting actual values of welding parameters. The variation of responses is presented graphically as shown in figures 9 , 10,11 and 12.

\subsection{Effect of processes parameters on HAZ width}

Figure 9 indicates that the HAZ width, in general increase with increase in wire feed rate and open circuit voltage while it decreases with the increase in welding speed with both the polarities

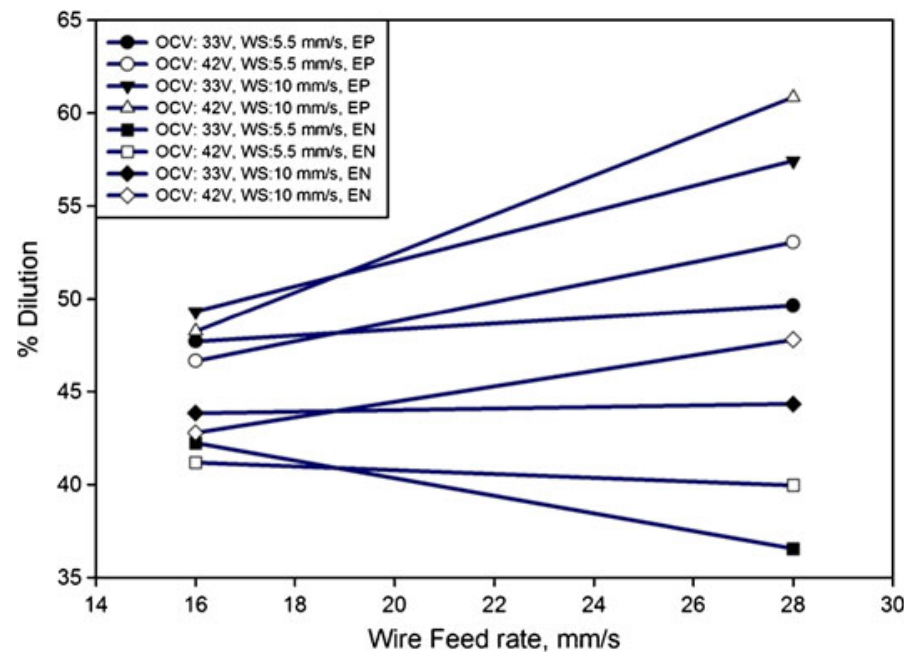

Figure 12. Interaction effects of process parameters on $\%$ dilution. 
i.e., electrode positive and electrode negative. It can be noted that at low open circuit voltage apparently there is no change in HAZ width with increase in wire feed rates, but at higher open circuit voltage, an increase is seen under electrode positive polarity. On the other hand, even at low open circuit voltage, HAZ width increases significantly with the increase in wire feed rates but rate of increase is not influenced by high open circuit voltage under electrode negative. Main effect of polarity is not so significant as compared to other variables, but it has interactive influence with wire feed rates. It is noticed that low wire feed rates under electrode positive produced wider HAZ as compared to electrode negative, but at high wire feed rates wider HAZ is obtained with electrode negative. It indicates that HAZ width is more sensitive to wire feed rates under electrode negative conditions. No interactions of welding speed are present with wire feed rates, open circuit voltage or polarity. From ANOVA table 4, it is found that open circuit voltage and welding speed with 43 and $31 \%$, respectively are the most effective parameters.

\subsection{Effect of processes parameters on HAZ area}

Mathematical model for HAZ area in coded form indicates that a reduction in HAZ area is favoured by decrease in wire feed rates and open circuit voltage. Figure 10 shows that smaller $\mathrm{HAZ}$ area can be produced by increasing welding speed. Again, the main effect of polarity is not influential but it has interaction with the wire feed rates similar to HAZ width. One can notice that at low wire feed rates HAZ area is higher at electrode positive under all similar variable combinations, while at high wire feed rates electrode negative polarity provides larger HAZ area. Hardly any effect of wire feed rates is observed on HAZ area with electrode positive but wire feed rates become more effective under electrode negative. In other words, electrode negative polarity with lower wire feed rates should be favoured for achieving small HAZ area during submerged arc welding. Like HAZ width, welding speed and open circuit voltage are most significant parameters which influence HAZ area (table 5).

\subsection{Effect of process parameters on heat input}

Heat input per unit length of weld is given by;

$$
H I=\eta \frac{I \times V}{S \times 1000}(k J / m m),
$$

where, $\mathrm{V}=$ arc voltage (Volt), $\mathrm{I}=$ welding current (Amp.), $\mathrm{S}=$ welding speed $(\mathrm{mm} / \mathrm{s})$ and $\eta=$ arc efficiency. In the present work, arc efficiency ' $\eta$ ' $=0.95$ is taken, which is the mean of the range of values reported for SAW process (Shen et al 2012; Easterling 1992).

Figure 11 indicates that the heat input to the weld pool increases with the increase in wire feed rates and open circuit voltage and a decrease in trend is seen with increase in welding speed under both polarities viz. electrode positive and electrode negative. Slightly less heat input with electrode negative is witnessed, compared to electrode positive. It is clearly observed from the interaction between wire feed rates and open circuit voltage that there is a reduction in the increase rate of heat input with respect to wire feed rate at lower open circuit voltages. Interaction between wire feed rates and welding speed reveals that rate of increase of heat input with respect to wire feed rates decreases at higher values of welding speed. Almost same is the case with electrode negative. Interaction effect of polarity with wire feed rate indicates that rise in heat input is more with electrode negative than electrode positive under all the similar conditions of open circuit voltage and welding speed. In that way electrode negative is more sensitive to 
change in welding parameters as far as the heat input is concerned. From the ANOVA analysis (table 6) of heat input, it is found that welding speed is the most influential parameter with $57 \%$ contribution.

\subsection{Effect of process parameters on \% dilution}

Dilution is ratio of weight of parent metal melted to the total weight of the fused metal and is expressed as the percentage dilution. Control of dilution levels is of much importance in welding applications. In similar metal joining, one needs to have maximum dilution, while in case of dissimilar metal joining like hardfacing and cladding, etc., need for minimum dilution arises. Therefore, it is quite useful to study the effects of welding parameters on dilution levels. It was found from the statistical analysis that electrode polarity and the weld travel speed are the most significant parameters that affect dilution. Developed models show that all the welding parameters have positive main effects on dilution i.e., an increase in wire feed rates, open circuit voltage, and welding speed favour higher dilution percentage.

However, from table 7 , it is observed that polarity is the most influential main effect with a contribution of $57 \%$ in the proposed model. As evident from figure 12, changing electrode negative from electrode positive, a sharp decrease in dilution takes place with the same wire feed rate and open circuit voltage. This decrease in dilution is the result of reduced welding current and in turn, arc force which finally affects penetration capability of the arc. Melting rate of the electrode is not affected to that extent with the decrease in welding current as the simultaneous increase in arc voltage makes up some of the heat input. So, a large reduction in penetration compared to that in deposited metal, lead to lower dilution levels. Wire feed rate seems not so significant in controlling dilution. An interaction of polarity is present with wire feed rates. A rise in dilution is seen with wire feed rates at electrode positive but the trend is reversed at electrode negative.

An interaction between welding speed and wire feed rates in figure 12 shows that high welding speed sharpen the effects of wire feed rates on dilution enhancement with electrode positive, while the effects are not so sound in case of electrode negative. Open circuit voltage as main effect does not affect dilution, but its interaction with wire feed rates illustrates that high open circuit voltage enhance the effectiveness of wire feed rates in positive electrode polarity. At lower welding speeds reinforcement area will be on higher side due to increased deposition per unit length of the weld. The bigger molten pool will prevent arc to penetrate deeper, which in turn may lead to lower dilution levels. However, higher welding speeds may lead to low penetration values but simultaneously a sharper decrease in the deposition rate per unit length of the weld will result in higher dilution levels.

\subsection{Effect of heat input on HAZ size and dilution}

Heat input in submerged arc welding depends on welding current, voltage and speed eq. (16). Effect of heat input on the responses is a reflection of what combination of current, voltage and speed has been used in producing said amount of heat input. The study of the influence of heat input is important, because power sources can be used more efficiently if one knows how same heat input can be applied to get the desired results. In this part, four heat input levels i.e., $700,1000,1300$ and $1600 \mathrm{~J} / \mathrm{mm}$ were selected for both electrode polarities to study the effect on dilution and HAZ area. For each level of heat input, welding current, welding voltage and welding speed were so varied that heat input remained constant and corresponding changes in 


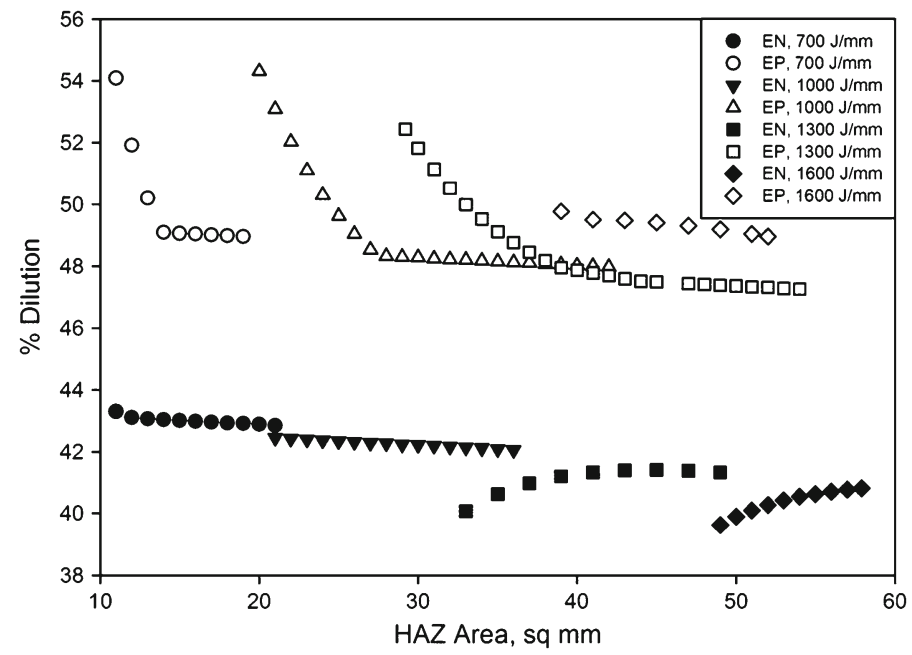

Figure 13. Effect of heat input on $\mathrm{HAZ}$ area and dilution (EN- electrode negative, EP- electrode positive).

HAZ area and \% dilution were noted down and plotted as illustrated in figures 13-16 using SYSTAT sigma plot software. Following conclusions were drawn from the observations.

5.5a Effect of heat input on dilution: A careful study of figure 13 indicates that for any level of the heat input, electrode positive gives higher dilution. A wide range of dilution (47-55\%) could be achieved under the given heat input conditions, when electrode is kept positive. It is also noted that variation subsides as large heat inputs are used. Figures 14-16 show the corresponding welding current, voltage and speed, which result in dilution values shown in figure 13. It is clearly indicated that the higher dilution is associated with high welding current, high speed and

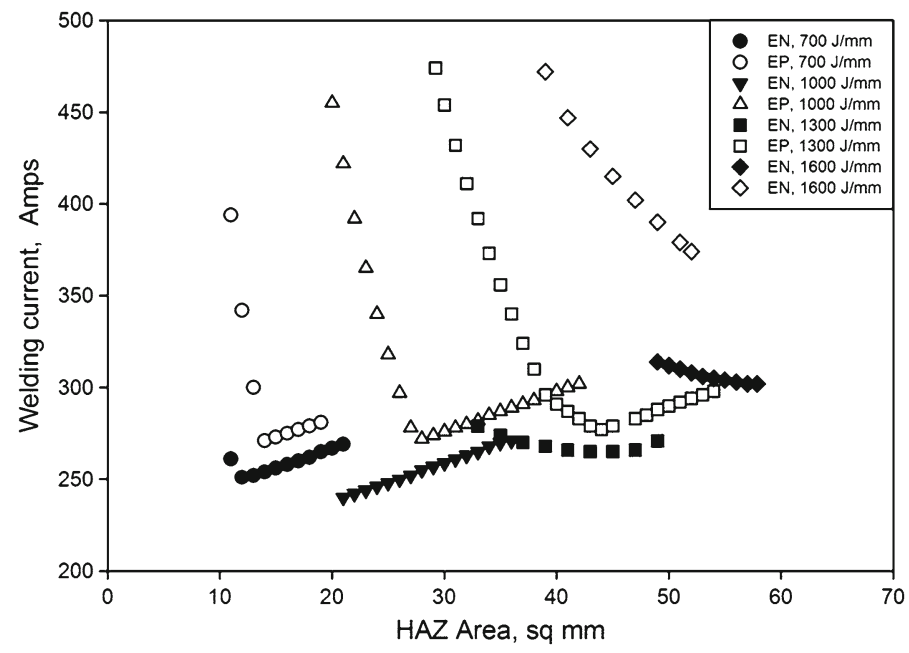

Figure 14. Variation of welding current and HAZ area with heat input (EN- electrode negative, EPelectrode positive). 


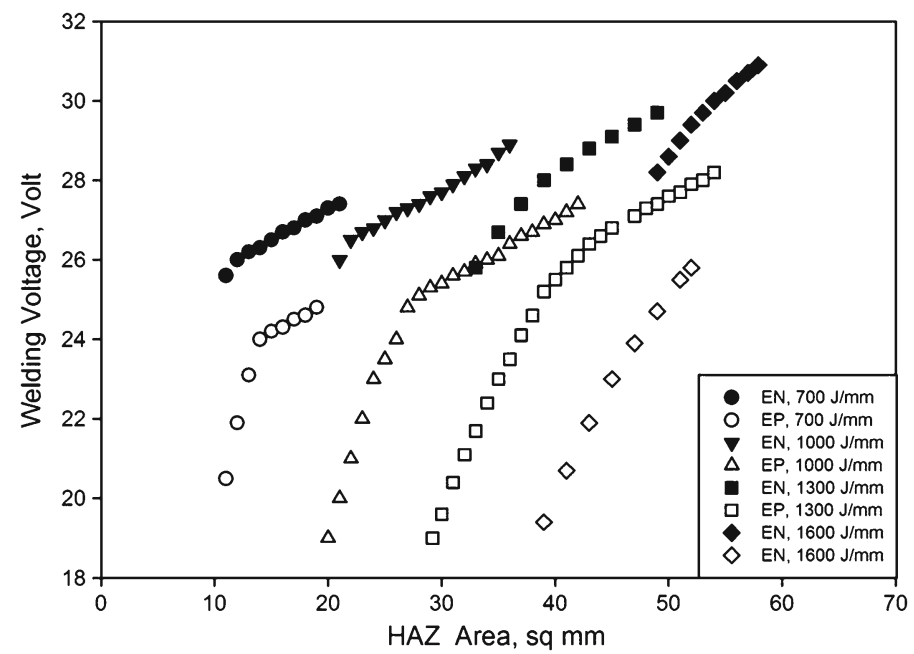

Figure 15. Variation of welding voltage and HAZ area with heat input (EN- electrode negative, EPelectrode positive).

low welding voltage. It is beneficial in joining thick sections using same heat input, where higher dilution is needed.

It can be noted from figure 13 that dilution is not significantly affected by heat input with electrode negative and an appreciable range of heat input $(700-1600 \mathrm{~J} / \mathrm{mm})$ can be used to achieve almost constant dilution (40-43\%). This result supports earlier work by Shen et al (2012), Clark (1985). Slight variation is seen at higher heat input levels i.e., 1300 and $1600 \mathrm{~J} / \mathrm{mm}$. Welding current for electrode negative, as shown in figure 14, varies from $240 \mathrm{~A}$ to $270 \mathrm{~A}$ for heat input from 700 to $1300 \mathrm{~J} / \mathrm{mm}$. For $1600 \mathrm{~J} / \mathrm{mm}$ heat input, little higher current (300-320A) is

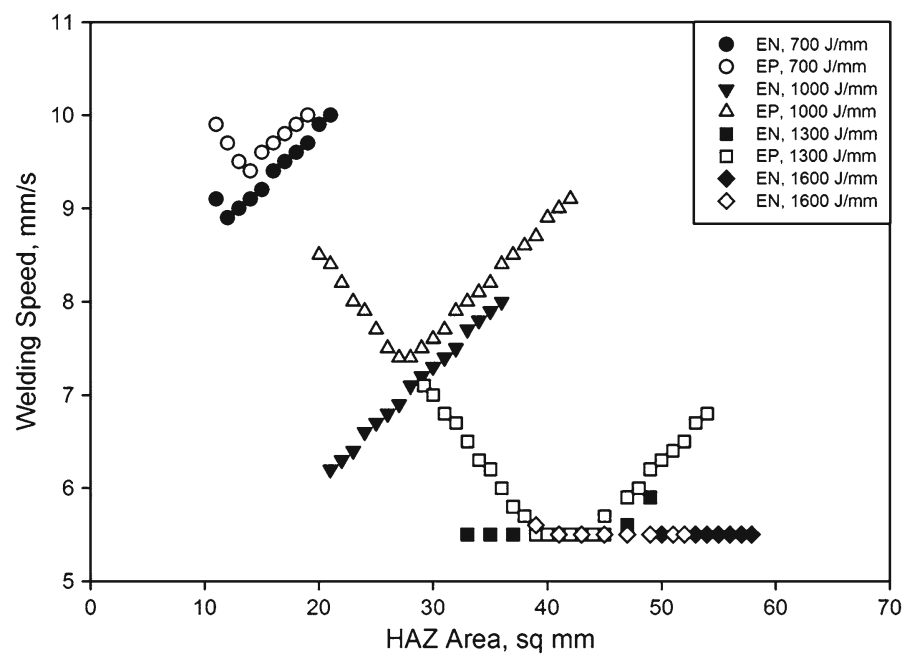

Figure 16. Variation of welding speed and HAZ area with heat input (EN- electrode negative, EPelectrode positive). 
needed, however for individual heat input levels, variation is small. From figures 15 and 16 corresponding values of welding voltage and speed can be noted. For elevated heat input, in general, higher welding voltage and lower welding speed is desired.

5.5b Effect of heat input on HAZ: In figures 13-16, it is evident that HAZ area shows a general increasing trend with heat input per unit length for both the polarities. Minimum HAZ area, that might be obtained with respect to four levels of heat input in ascending order, were found to be $10,19,29$ and $38 \mathrm{~mm}^{2}$ for negative polarity and 11, 21, 32 and $48 \mathrm{~mm}^{2}$ for positive polarity as depicted in figure 13. At any given heat input condition, small HAZ size is achieved using high welding current, low welding voltage and high welding speeds as can be seen in figures 14-16. High welding voltages at any heat input level always tend to produce wider HAZ. A band of HAZ area (e.g., 21-36 $\mathrm{mm}^{2}$ at $1000 \mathrm{~J} / \mathrm{mm}$ ) can be produced with almost constant dilution and at definite heat input level. This is because of the variations occurring in bead geometry parameters arising out of changes in welding current, voltage and speed. Overlapping of range of HAZ area is also observed for both the polarities. In other words, same HAZ area might be obtained in the overlapping range but at the cost of increased dilution with electrode positive.

\subsection{Validation of models}

Models for HAZ area and heat input represented in eqn. (5-6) can be validated by the models developed by Gunaraj \& Murugan (1999a) through their work to find out the effect of process parameters on the heat input and HAZ area produced in SAW of pipes. A five level four factor (wire feed rate, welding speed, open circuit voltage and nozzle to plate distance) rotatable central composite factorial design was used to develop models for HAZ area and heat input. That is the only work which had been carried out in the past to model HAZ area for SAW process that too using electrode positive polarity only. Trends exhibited for HAZ area and heat input with respect to process parameters in the present work show good conformity with the results obtained by Gunaraj and Murugan. This comparison becomes more important as the process parameter window shown in table 1 lies well within that used by these authors. Slight variation can be attributed to difference in other conditions like plate thickness of $6 \mathrm{~mm}$ was used instead of $10 \mathrm{~mm}$ in the present work. Effect of heat input on HAZ area in the present work is also found similar as reported by these authors i.e., average HAZ area has linear relationship with heat input as described in section 5.5b and figure 13. This shows that two level fractional factorial designs can provide useful information if conditions do not allow the use of more complex design of experiments.

\section{Conclusions}

The present work is an effort to quantify the effect of SAW parameters on heat input, HAZ size and dilution. Following conclusions can be drawn from the study.

(i) Two level factorial design techniques have been used to develop mathematical models for predicting heat input, HAZ size and dilution in submerged arc welding and cladding process.

(ii) Effect of process variables on heat input follows similar trend for both the polarities being slightly on lesser side for electrode negative. However, rise in heat input on increasing wire feed rate is more pronounced with electrode negative. This can be attributed to the fact 
that a narrower bead width is produced while using negative electrode polarity (Yang et al 1992). This leads to increased heat input density on the base metal as the current levels are increased.

(iii) HAZ width/area rises more effectively with wire feed rate at all the levels of open circuit voltage under electrode negative condition. Again the reason for wider HAZ is increased heat input concentration as the bead gets narrower and more heat per unit area is transferred into base metal which in turn alters its metallurgy deeper into base metal.

(iv) Influence of process variables on HAZ area is found similar to that on HAZ width. However, electrode negative polarity produces lesser HAZ under all conditions, in general, except at higher wire feed rates.

(v) Electrode polarity influences $\%$ dilution significantly. More than $20 \%$ decrease in dilution is observed with negative polarity as seen from figure 13. As lower dilution is achieved with electrode negative, submerged arc welding can be efficiently used for cladding, hardfacing, etc., and still maintaining high deposition rates. In view of this, use of SAW with negative polarity has been suggested by several researchers for surfacing applications (ASM 1993; Chandel 1987; Yang et al 1993).

(vi) HAZ area varies almost linearly with heat input i.e., low values of HAZ width/area can be achieved keeping the heat input on lower side for both polarity conditions.

\section{References}

Adler Y P 1975 The design of experiments to find optimal conditions. Moscow: Mir Publishers

Anderson V L and McLean R A 1974 Design of experiments-a realistic approach. New York: Marcel Dekker, Inc

ASM 1993 Welding, Brazing and soldering, vol 6. ASM Handbook. USA: ASM International

Chandel R S 1987 Mathematical modeling of melting rates for submerged arc welding. Welding Journal, Welding Research Supplements:135s-140s

Chandel R S, Seow H P and Cheong F L 1997 Effect of increasing deposition rate on the bead geometry of submerged arc welds. J. Materials Processing Technol. 72(1):124-128

Clark J N 1985 Manual metal arc weld modelling. Part 1. Effect of process parameters on dimensions of weld bead and heat-affected zone. Mater. Sci. Technol. 1:1069-1079

Dhas J E R and Kumanan S 2011 Optimization of parameters of submerged arc weld using non conventional techniques. Appl. Soft Comput. 11(8): 5198-5204

Easterling K E 1992 Introduction to the physical metallurgy of welding. 2nd edn. Oxford: ButterworthHeinemann Ltd

Fnides B, Yallese M A, Mabrouki T and Rigal J F 2011 Application of response surface methodology for determining cutting force model in turning hardened AISI H11 hot work tool steel. Sadhana 36(1): $109-123$

Ghosh A, Chattopadhyaya S, Das R K and Sarkar P K 2011a Assessment of heat affected zone of submerged arc welding process through digital image processing. Procedia Engineering 10: 2782-2785

Ghosh A, Chattopadhyaya S, Das R K and Sarkar P K 2011b Prediction of submerged arc welding yield parameters through graphical technique. Procedia Engineering 10: 2797-2802

Ghosh A, Chattopadhyaya S and Sarkar P K 2011c Critical analysis of confounded parameters of SAW process. Procedia Engineering 10: 2786-2790

Gunaraj V and Murugan N 1999a Prediction and comparison of the area of the heat-affected zone for the bead-on-plate and bead-on-joint in submerged arc welding of pipes. J. Materials Processing Technol. 95(1-3): 246-261

Gunaraj V and Murugan N 1999b Application of response surface methodology for predicting weld bead quality in submerged arc welding of pipes. J. Materials Processing Technol. 88(1-3): 266-275 
Karaoğlu S and Seçgin A 2008 Sensitivity analysis of submerged arc welding process parameters. J. Materials Processing Technol. 202(1-3): 500-507

Khallaf M E, Ibrahim M A, El-Mahallawy N A and Taha M A 1997 On crack susceptibility in the submerged arc welding of medium-carbon steel plates. J. Materials Processing Technol. 68(1): 43-49

Kou S 2003 Welding metallurgy. 2nd edn. USA: John Wiley \& Sons, Inc

Lancaster J F 1993 Metallurgy of welding. 5th edn. London: Chapman \& Hall

Mason R L, Gunst R F and Hess J L 2003 Statistical design and analysis of experiments Wiley Series in probability and statistics, 2nd edn. New Jersey: John Wiley \& Sons, Inc

Montgomery D C 2001 Design and analysis of experiments. 5th edn. Singapore: John Wiley \& sons Inc

Murugan N and Gunaraj V 2005 Prediction and control of weld bead geometry and shape relationships in submerged arc welding of pipes. J. Materials Processing Technol. 168(3): 478-487

Murugan N and Parmar R S 1993 Effect of submerged arc process variables on dilution and bead geometry in single wire surfacing. J. Materials Processing Technol. 37: 767-780

Om H and Pandey S 2010 Effect of electrode polarity in submerged arc welding process. Paper presented at the Twenty fourth Indian Engineering Congress, NIT Surathkal, Mangalore, India, December, 10-13

Pandey N D, Bharti A and Gupta S R 1994 Effect of submerged arc welding parameters and fluxes on element transfer behaviour and weld-metal chemistry. J. Materials Processing Technol. 40(1-2): $195-211$

Pandey S 2004 Welding current and melting rate in submerged arc welding: A new approach. Australasian Welding Journal Supplements 49(Second Quarter): 33-42

Shen S, Oguocha I N A and Yannacopoulos S 2012 Effect of heat input on weld bead geometry of submerged arc welded ASTM A709 Grade 50 steel joints. J. Materials Processing Technol. 212(1): 286-294

Tušek J 2000 Mathematical modeling of melting rate in twin-wire welding. J. Materials Processing Technol. 100(1-3): 250-256

Wen S W, Hilton P and Farrugia D C J 2001 Finite element modelling of a submerged arc welding process. J. Materials Processing Technol. 119(1-3): 203-209

Yang L J, Chandel R S and Bibby M J 1992 The effects of process variables on the bead width of submerged-arc weld deposits. J. Materials Processing Technol. 29(1-3): 133-144

Yang L J, Chandel R S and Bibby M J 1993 The effects of process variables on the weld deposit area of submerged arc welds. Welding Journal Welding Research Supplements: 11s-18s 